\title{
Verification of a novel innovative blade root design for wind turbines using a hybrid numerical method
}

Zhu, Wei Jun; Shen, Wen Zhong; Sørensen, Jens Nørkær; Yang, Hua

Published in:

Energy

Link to article, DOI:

10.1016/j.energy.2017.11.091

Publication date:

2017

Document Version

Peer reviewed version

Link back to DTU Orbit

Citation (APA):

Zhu, W. J., Shen, W. Z., Sørensen, J. N., \& Yang, H. (2017). Verification of a novel innovative blade root design for wind turbines using a hybrid numerical method. Energy, 141, 1661-1670.

https://doi.org/10.1016/j.energy.2017.11.091

\section{General rights}

Copyright and moral rights for the publications made accessible in the public portal are retained by the authors and/or other copyright owners and it is a condition of accessing publications that users recognise and abide by the legal requirements associated with these rights.

- Users may download and print one copy of any publication from the public portal for the purpose of private study or research.

- You may not further distribute the material or use it for any profit-making activity or commercial gain

- You may freely distribute the URL identifying the publication in the public portal 


\section{Accepted Manuscript}

Verification of a novel innovative blade root design for wind turbines using a hybrid numerical method

Wei Jun Zhu, Wen Zhong Shen, Jens Nørkær Sørensen, Hua Yang

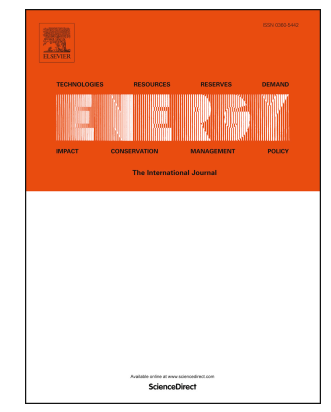

PII:

S0360-5442(17)31949-7

DOI:

10.1016/j.energy.2017.11.091

Reference: EGY 11879

To appear in: Energy

Received Date: 22 July 2017

Revised Date: 24 October 2017

Accepted Date: 15 November 2017

Please cite this article as: Zhu WJ, Shen WZ, Sørensen JensNøæ, Yang H, Verification of a novel innovative blade root design for wind turbines using a hybrid numerical method, Energy (2017), doi: 10.1016/j.energy.2017.11.091.

This is a PDF file of an unedited manuscript that has been accepted for publication. As a service to our customers we are providing this early version of the manuscript. The manuscript will undergo copyediting, typesetting, and review of the resulting proof before it is published in its final form. Please note that during the production process errors may be discovered which could affect the content, and all legal disclaimers that apply to the journal pertain. 


\title{
Verification of a Novel Innovative Blade Root Design for Wind Turbines using a Hybrid Numerical Method
}

4

(1)

\author{
ABSTRACT
}

To enhance the performance of horizontal axis wind turbines, it is proposed to place a cylindrical disc in front of the rotor in order to lead the incoming flow from the inner part to the outer part of the rotor blades. This is expected to increase the power output, as the kinetic energy is mainly captured at the outer part of the blades, where the relative wind speed is high. To assess the impact of this novel design idea, a hybrid numerical technique, based on solving the Reynolds-averaged Navier-Stokes equations, is utilized to determine the aerodynamic performance. The in-house developed EllipSys3D code, which is employed as basic numerical solver, is combined with an actuator disc representation of the wind turbine rotor and an immersed boundary technique for representing the upstream cylindrical disc. The impact of the disc on the rotor performance is assessed by systematically changing the size of the circular disc and its axial distance to the rotor. Based on a numerical study of a Megawatt size commercial wind turbine, it is found that up to $1.5 \%$ additional energy can be captured by placing a circular disc with a suitable diameter upstream of the rotor plane.

\section{Keywords}

Root loss; Optimal design; Aerodynamic performance; Computational Fluid Dynamics.

\section{Nomenclature}

$5 \quad$ Disc area


26

$a_{i}, a_{p}$

$27 \quad b$

$28 \quad C p$

$29 d$

$30 \quad d^{*}$

$31 \boldsymbol{f}_{A D}$

$32 f_{I B}$

$33 \boldsymbol{f}^{\prime}$

$34 r^{*}$

$35 \quad \operatorname{Re}$

$36 S$

$37 \quad T$

$38 \bar{u}$

$39 u_{d}$

$40 \quad U$

$41 \quad U_{d}$

$42 U$

$43 v_{i}$

$44 x, y, z$

$45 \Delta z$

$46 \rho$

$47 \delta$

$48 v$

$49 \epsilon$

$50 \quad \eta$

51 CFD

52 IB
Coefficients

Wake width

Pressure coefficient / power coefficient

Normal distance

Axial distance between a disc and a rotor

Body force of an actuator disc wind turbine rotor

Body force of an immersed boundary

Smeared body force of a rotor disc

Radius of the circular disc

Reynolds number

Momentum source

Thrust

Mean axial induction

Wake deficit

Free stream velocity

Maximum wake deficit

Velocity vector

Cell centre velocity at immersed boundary

Cartesian coordinates

Typical grid size

Fluid density

Boundary layer thickness

Fluid kinematic viscosity

Smearing factor

Convolution kernel function

Computational Fluid Dynamics

Immersed Boundary 


\section{Introduction}

Although the aerodynamic knowledge achieved in the past decades has contributed greatly to increase the performance and efficiency of wind turbine rotors, it is evident that increasing the power efficiency is still a major task for designers of modern wind turbines. The success of the aerodynamic progress is best illustrated by the change in rotor design from the relatively over-dimensioned $\mathrm{kW}$ size turbines in the 1980's [1] to the slender MW size turbines developed in recent years [2], [3], [4]. An evaluation of the wind power planning in Denmark showed that there is clearly a tendency to exclude smaller turbines in future design developments [5]. To capture more energy, a straightforward technique is to increase the rotor size and thereby increase the turbine capacity, as illustrated by the newly developed Vestas 9.5MW wind turbine, which has a rotor diameter of 164 meters. However, extending the rotor length requires the development of new lightweight materials and causes logistic problems associated with transportation, and the construction and erection the rotor blades. Furthermore, issues regarding public acceptance limits the size of wind turbines on onshore sites. In order to increase the performance of wind turbines located on onshore sites it is therefore required to focus on optimal aerodynamic design solutions. A key to a better aerodynamic performance is the development of robust airfoils with a high lift to drag ratio and a low noise level [6], [7], [8], [9], combined with optimized blade plan forms [10], [11], [12]. Some of the blade optimization works also change the blade thickness by re-designing the structural parameters [13]. More advanced designs techniques combine the airfoil design and blade design together, in order to develop airfoils fitted to desired flow conditions [2], [14]. However, the aerodynamic performance near the blade root is less studied, and a generally poor aerodynamic performance in the blade root region is considered a problem that cannot be directly solved with conventional design techniques.

In terms of geometrical complexity, the previous mentioned works are based on traditional design technologies. More recent research concerns unconventional blade plan forms, such as serrated leading edge geometries, inspired by the bionic structure of whales [15], which may reduce the drag and delay stall, or serrated trailing edges, inspired by the feather of owls, to reduce the aerodynamic noise [16]. Other add-ons, such as vortex generators, are already implemented on commercial wind turbines [17]. Newer research 
81 efforts are directed towards the use of so-called smart blade techniques in wind turbines. This term refers essentially to various morphing technologies utilized to change the lift and drag coefficients dynamically, in order to improve the aerodynamic efficiency and to reduce the loads while operating the turbine. This is accomplished either by changing the aerodynamic geometry through ailerons, trailing edge or leading edge flaps, or through deformable structures with flexible skin and continuous surfaces with particular characteristics [18].

The design objective of the current work is the same as for 'smart' blades. The idea is to place a circular disc in front of the rotor in order to redistribute the incoming flow by leading it from the inner part to the its operational conditions are not changed, which keeps the wind turbine system almost the same as the one of the original rotor. Practically, the concept can be directly applied on any existing horizontal axis wind turbine. A sketch of a rotor configuration with an additional circular disc is shown in Figure 1. The present developed rotor EllipSys3D flow solver [23], [24] is employed as platform for the computations. The flow work was inspired by an interesting experimental project carried out by the wind turbine manufacturer GE Wind Energy [19], with the ambition of increasing the power generation with up to $3 \%$ by improvements near the blade root. As it is a new concept that has not been studied systematically before, we here propose to start with a numerical investigation to reveal the flow physics behind the design. Hence, the objective of the present work is to validate the concept numerically by introducing a circular disc in front of an existing rotor and compute the resulting flow characteristics and power performance of the turbine. First, a computation employing a full 3D body-fitted mesh encompassing the rotor and the disc is carried out to verify if the concept with the add-on results in an improved aerodynamic performance. Next, to reduce the computational effort in a subsequent optimization study, the circular disc and the rotor blade are simulated in a 3D Cartesian grid using a hybrid numerical method in which the circular disc is modelled with a cell-blocking immersed boundary method [20], [21] and the rotor is represented by an actuator disc [22]. The in-house interaction between the rotor and the circular disc is simulated parametrically by changing the disc size and the distance to the rotor plane. 
The paper is organized as follows: Section 2 introduces the numerical techniques; Section 3 presents numerical results using both full CFD and actuator disc simulations with and without a front circular disc;

110 Conclusions are given in the final section.

\section{Numerical features}

\section{$112 \quad 2.1$ The basic flow solver}

113 As indicated in Figure 1, the flow field becomes more complicated when coupling a disc with a rotor.

114 Although engineering models exist for both circular disc and wind turbine rotor, the combined flow field can 115 hardly be modelled by any existing engineering methods, hence it is required to resort to 3D Navier-Stokes 116 solvers. In the present work, the numerical results are obtained using the 3D Navier-Stokes solver EllipSys 117 [23], [24] as basic numerical platform. This solver is based on a second-order multi-block finite volume 118 method. It solves the velocity-pressure coupled Reynolds-averaged Navier-Stokes equations with options of 119 using the SIMPLE/SIMPLEC/PISO algorithms and a multi-grid strategy. The momentum equations are first solved with a guessed pressure as a predictor. Next, the continuity equation is used as a constraint to obtain an equation for the pressure correction. In the predictor step, the momentum equations are solved by a second-order accurate backward scheme in time. For the spatial discretization a central difference scheme is employed for the diffusive terms and the QUICK upwind scheme is utilized for the convective terms. In the corrector step, the improved Rhie-Chow interpolation technique is applied to suppress numerical oscillations from velocity-pressure decoupling. Furthermore, an improved SIMPLEC scheme developed for collocated grids is used in order to ensure that the solution does not depend on the values of relaxation parameters and time-step. The Navier-Stokes equations are discretized using a finite-volume scheme and all the information from the grid geometry is directly transferred into the discretized terms.

\subsection{The immersed boundary approach}

The idea behind the simulations is to identify the possibilities of further energy capture and 131 consequently provide a best configuration of the disc size and the axial location. This requires a large 132 number of simulations. To avoid re-meshing the geometry for each simulation, the circular disc is modelled 133 with an Immersed Boundary (IB) method, which is aimed for flows over moving bodies or complex 
134

geometries [20] [21] [25]. To demonstrate the basic features of the IB technique, the Navier-Stokes equations are shown below,

$$
\partial \boldsymbol{U} / \partial t+\boldsymbol{U} \cdot \nabla \boldsymbol{U}=-\frac{1}{\rho} \nabla p+\nu \nabla^{2} \boldsymbol{U}+\boldsymbol{f}_{I \boldsymbol{B}}
$$

where the left-hand side denotes the transport terms of the velocity $\boldsymbol{U}, p$ is the pressure, $\rho$ the density of air, $V$ is the kinematic viscosity, and the extra term $f_{I B}$ is the body force calculated at the immersed boundary surface. The forcing term $f_{I B}$ is updated at each time step based on the calculated velocity at the forcing cells, such as

$$
\boldsymbol{f}_{\boldsymbol{I B}}=-S+\sum_{i=1,6} a_{i} \boldsymbol{U}_{\boldsymbol{i}}+\boldsymbol{v}_{\boldsymbol{i}} a_{p},
$$

where $S$ is the source term, $\sum$ is the compass summation notation, subscript $p$ denotes the centre node, $a_{i}$ are the influence coefficients of neighbouring cells, and $a_{p}$ is the center node influence coefficient. The velocity $v_{i}$ at the IB cells is obtained by linear or bilinear interpolation between the IB surface velocity (zero for nonmoving case) and the velocity at the neighbouring grid cells.

The IB approach is for several reasons well-fitted in the current study: (1) The size and position of the disc can easily be changed, hence the CPU time is significantly reduced without mesh regeneration; (2) The mesh is aligned with the disc surface, which is the most accurate case for the IB method; (3) The simple mesh configuration solves the mesh problem for the circular disc, as well as for the wind turbine, provided that the rotor is replaced by an actuator disc.

\subsection{The actuator disc approach}

The idea with the actuator disc concept is to replace the rotor by a disc representing the loading on the rotor. In the original method, this was accomplished by using tabulated airfoil data [26], but in many cases a simple constant loading is applied [22], [27], [28]. Today, the actuator disc technique has been supplemented by more sophisticated methods, such as the actuator line [29], [30], [31] and the actuator surface methods [32]. In spite of their approximate nature, the methods in general exhibit a good numerical accuracy and they are much faster than conventional mesh-based rotor computations. In the present study the rotor is represented by an actuator disc, which is implemented in the EllipSys solver using tabulated airfoil data. To 
represent the effect from the actuator disc, the body forces are added to the momentum equation, as shown

161 below,

$$
\partial \boldsymbol{U} / \partial t+\boldsymbol{U} \cdot \nabla \boldsymbol{U}=-\frac{1}{\rho} \nabla p+v \nabla^{2} \boldsymbol{U}+\boldsymbol{f}_{A \boldsymbol{D}}
$$

As the disc is assumed permeable, the mass equation remains unchanged. In the equation, the term $f_{A D}$ is the body force representing the loading of the wind turbine rotor. The body force needs to be smoothly redistributed to prevent numerical oscillations and to ensure that the integrated loading is conserved. As the disc appears as a 1D line in the axisymmetric plane, a 1D Gaussian filtering approach is applied to redistribute the forces away from the disc. In the current model, each force element is filtered in the normal direction with a distance $d$ away from the disc according to the convolution

$$
\boldsymbol{f}^{\prime}=\boldsymbol{f}_{A D} \otimes \eta^{1 D},
$$

with the smearing force $\boldsymbol{f}^{\prime}$ computed as

$$
\eta^{1 D}(d)=1 /(\epsilon \sqrt{\pi}) \exp \left[-(d / \epsilon)^{2}\right]
$$

\section{Results and discussions}

\subsection{Full CFD rotor simulations}

\section{5}

\subsubsection{Mesh and turbulence model}

As a typical MW size wind turbine, the 2.5 MW NM80 wind turbine located at the Tjæreborg site in Denmark, is chosen for the present study. The geometrical data, as well as some experimental data, are available, which makes it easier to carry out the current study. The rotor has a radius of $40 \mathrm{~m}$ and the tip speed is regulated at wind speeds below the rated one, to operate at optimum power at low wind speeds, and pitch regulated at wind speeds higher than the rated one to maintain a constant power performance at high wind speeds.

In the simulations, the wind turbine is assumed to operate at a wind speed smaller than the rated one, hence it is assumed to operate at its optimum conditions. The wall surface mesh is shown in Figure 2 for both the original wind turbine and a version with a circular disc positioned in front of the rotor. The total number of 
mesh points used for the two rotors are 16.5 million and 20.5 million, respectively. The first wall cell height is less than $10^{-6} \mathrm{~m}$ and the resulting $\mathrm{y}^{+}$-values are well below 1 , which is deemed sufficient for resolving the boundary layer.

In Figure 3, the dimensionless wall distance is computed at a wind speed of $10 \mathrm{~m} / \mathrm{s}$, where it can be seen that the largest $\mathrm{y}^{+}$-value appears near the blade tip. To model the boundary layer characteristics, the $\mathrm{k}-\omega \mathrm{SST}$ model of Menter [33] is used together with a transitional boundary flow model.

\subsubsection{Basic validation of flow solver without disc}

Quite some comprehensive studies of the NM80 wind turbine were previously carried through the Danaero project [34]. Some of the data from the field measurements are used to validate the present CFD simulations. The blade surface pressure distributions were measured at four spanwise locations $r=12,19,30$ and $37 \mathrm{~m}$, measured from the blade root towards the tip. At a wind speed of $6.1 \mathrm{~m} / \mathrm{s}$, the wind turbine was running in a non-sheared flow situation at a nearly constant rotational speed of 12.1 RPM and a constant pitch angle of $0.15^{\circ}$. With the full CFD simulation, it is possible to identify detailed load distributions at all blade sections, as well as pressure distributions along the four measured blade sections. Figure 4 shows the rotor simulation and the measured surface pressure data. At all the four locations, very good agreements are achieved even though the data are obtained from outdoor measurements.

\subsubsection{Influence of the disc}

In order to illustrate the effect of the circular disc, grouped streamlines are injected near the blade root. In Figure 5, the streamlines passing through the two rotors are shown at the same locations. To more clearly illustrate the impact of the cylinder, only the streamlines through a single blade is shown. As seen from the streamlines, the presence of the circular disc causes the flow through the root to become more skewed with a larger recirculation seen from the wake. Comparing with the original rotor, the streamlines show that flow expansions clearly exist, especially near the edge of the disc. It is likely that the effect from the disc is gradually decreased at the outer board of blade. 
The aerodynamic loads of the original rotor and the rotor with a disc are first investigated at a wind speed

214 of $10 \mathrm{~m} / \mathrm{s}$, corresponding to the expected mechanical power of $1.5 \mathrm{MW}$. Pressure distributions from $\mathrm{r}=8 \mathrm{~m}$ to $215 \mathrm{r}=30 \mathrm{~m}$ are shown in Figure 6 where $C p$ and $C p d$ denote the pressure coefficients for the original rotor and for 216 the rotor with an added disc. In Figure 6 (a), the difference of pressure distribution on the suction side is 217 quite large, and the existence of the disc largely changes the flow separation at $\mathrm{r}=8 \mathrm{~m}$. In Figure 6 (b), the two $218 C p$ curves are closer, but the difference between $C p$ and $C p d$ is still evident. When moving further towards 219 the tip, less flow separation occurs due to a smaller angle of attack over the outer board thinner airfoil sections. From Figure 6 (c), (d), and (e), the trend is still clearly distinguishable, that the pressure force acting on these blade sections is larger for the case with the circular disc. At $r=14 \mathrm{~m}$ and $\mathrm{r}=16 \mathrm{~m}$, the difference from the $C p$ curves is quite small which is also difficult to distinguish. Starting from $\mathrm{r}=18 \mathrm{~m}$, the disc is seen to have little influence on the aerodynamic force where the two $C p$ curves almost collapse. Finally, as the most interesting part, the total pressure force and the rotor torque are compared in Table 1. Due to the larger integration area, the total pressure force is larger for the rotor with disc as expected, and the contribution from the smaller viscous force can be neglected. Integrating the tangential force along the blade, it is found that the rotor torque is increased about $1.65 \%$ as compared to the reference rotor. It is assumed that a good balance between the disc size and the axial spacing between the disc and the rotor plane provides best power output. It is worth noting that this full CFD simulation is selected as the ideal configuration, based on the parametrical study using the actuator disc method shown in the following section.

\subsection{Actuator disc simulations}

In the actuator disc simulations the parameter used in the smearing function is $\epsilon=3 \Delta z$, where $\Delta z$ is the reference grid size in the axis direction. The normalized blade thickness distribution of the rotor blades is blade thickness distribution, especially at the inboard part, is typical for most designs of modern wind turbines, including the newly designed extreme scale turbines $[2,35]$. The relation between blade root loss and the rotor size scales approximately as $\Delta p \propto R^{2}$. The energy loss at the root is even more for a larger rotor that has a higher tower and thus a higher hub-height wind speed. In Figure 7, the relative thickness of 
240 the last three sections is $100 \%, 100 \%$ and $96.5 \%$ at $r=0 \%, 3.6 \%$ and $8 \%$, respectively. From an 241 aerodynamic point of view, little power production is expected from this part of blade. The free stream wind 242 through the hub area will not be converted into effective shaft torque. Hence, there is a potential to optimize 243 the flow through the root part. Thus, a parametric study is preferred with a reasonably fast numerical tool, 244 such as the actuator disc method.

The flow field from one of the numerical calculations using the actuator disc method is illustrated in Figure 8 . The iso-vorticity plot shows the tip and root vortices where the root vortex is a combination of the flow over the circular disc and over the blade root itself. The change of the flow field near the root depends on both the distance between the disc and the rotor and on the size of circular disc.

To identify the influence from the circular disc, flow fields with and without the circular disc are compared. Figure 9 shows a top view of the axial velocity field near the rotor. The long straight line represents the rotor disc and the shorter line is the position of the circular disc. A larger power production is expected when the axial velocity into the rotor plane is large. But this is not the case for the blade inboard part, as shown on the left side of Figure 9. The axial velocity is large both before and after the rotor plane, which indicates partly loss of wind energy. The axial flow field with the circular disc is shown on the right side of Figure 9. The major difference is found near the root where the axial flow is heavily blocked by the circular disc. The flow is re-directed towards the middle part of the blade where some increase of axial velocity can be observed, for example near the position $r=0.3$. There is also an evidence of a velocity magnitude increase in the near wake indicating that more energy has been converted into the aerodynamic power with the added disc. A closer look at the axial velocity distribution is given in Figure 10 where the axial velocity of the original turbine and the optimized turbine is compared in the rotor plane. In the original case, the axial velocity is rather large near the root, but is largely reduced by the circular disc in the optimized case. In the middle part of the blade, an increase of axial velocity is clearly observed, which provides the evidence of the power increase.

To evaluate the change in power coefficient $C_{p}$, a large computational matrix is considered. The matrix contains two variables, the size of the circular disc $r^{*}$ and the axial distance $d^{*}$ to the rotor center. The radius 
of the circular disc is selected as: $r^{*} \in[0.03,0.05,0.07,0.08,0.085,0.09,0.1,0.12]$ and the separation

distance is $d^{*} \in[0.05,0.1,0.15,0.2,0.25,0.3]$, both normalized with the blade length. This gives in total 48 simulations, covering a relatively large number of degrees of freedom. The levels of the contour plot in

Fig. 11 show the $C_{p}$-difference in percentage of the reference $C_{\text {pref }}$ value obtained from the original rotor. A maximum $\Delta C_{p}=1.5 \%$ is found at $d^{*}=0.2$ and $r^{*}=0.085$. This is nearly an additional $40 \mathrm{~kW}$ power production at the rated power. The observations from the calculations are: (1) The disc radius $r^{*}$ is a sensitive value, which must be limited within an interval of 7-10\%; (2) Provided that the disc radius is properly chosen, the separation distance is less crucial, but should be within the interval 10-30\%; (3) A positive $\Delta C_{p}$ is found from most of the calculations, but a reduction of power is revealed at large $d^{*}$ and $r^{*}$. Comparing to other innovations, the advantage of the present design is low cost, low risk and no additional costs during wind turbine operation. As a passive flow control device, the idea can be applied directly to any existing three bladed horizontal axis wind turbine and may increase the performance of existing wind farms.

\section{Conclusions}

A novel horizontal axis wind turbine rotor system in which a circular disc is added in front of the main rotor is investigated numerically. The shape of the main rotor is unchanged. The design work is fully based on numerical calculations to evaluate the best configuration of the axial spacing and the size of the circular disc. To reduce the cost of the CFD simulations, the wind turbine rotor is modelled as an actuator disc, which is a well-known approach in wind turbine aerodynamics. The standard way of meshing around the small circular disc in front of the main rotor will damage the overall advantage of the actuator disc method. Hence, to avoid making a new mesh for each computation and to facilitate the use of the actuator disc, the immersed boundary method is employed for representing the disc. This is a numerical approach similar to the actuator disc technique, which, favoured by the Cartesian mesh, virtually represents the circular disc by body forces. Benefitted by the computational efficiency of combining the actuator disc approach with an immersed boundary technique, a test matrix of 3D CFD simulations is then carried out in a given range of axial spacing and disc radius. The resulting maximum gain in relative power is found to be around $1.5 \%$, which is computed with a disc radius of $0.085 \mathrm{R}$ and an axial spacing of $0.2 \mathrm{R}$. The power is found to increase in most 
of the simulations, as long as the disc size is not too large, which starts to block the flow though the effective

296 blade elements at the outer part. This is so far the first numerical attempt to make a proof of concept, and 297 some future work can be made to further optimize the shape of the disc, which, however, may require more 298 sophisticated numerical methods.

\section{Acknowledgement}

301 The authors wish to express acknowledgement to the National Nature Science Foundation under grant 302 number 11672261.

\section{References}

305 [1] Fleming PD, Probert SD. The evolution of wind-turbines: An historical review. Applied Energy 1984; $18(3): 163-177$.

[2] Zhu WJ, Shen WZ, Sørensen JN Integrated airfoil and blade design method for large wind turbines. Renewable Energy 2014; 70: 172-183. DOI:10.1016/j.renene.2014.02.057.

309 [3] Horcas SG, Debrabandere F, Tartinville B, Hirsch C, Coussement G. Rotor-tower interactions of DTU

[4] Loth E, Steele A, Qin C, Ichter B, Selig MS, Moriarty P. Downwind pre-aligned rotors for extremescale wind turbines. Wind Energy 2017; 20(7); 1241-1259. DOI: 10.1002/we.2092.

314 [5] Sperling K, Hvelplund F, Mathiesen BV. Evaluation of wind power planning in Denmark - Towards an integrated perspective. Energy 2010; 25(12); 5443-5454. 10MW reference wind turbine with a non-linear harmonic method. Wind Energy 2017; 20(4); 619636. DOI: $10.1002 /$ we.2027.

[6] Göçmen T, Özerdem B. Airfoil optimization for noise emission problem and aerodynamic performance criterion on small scale wind turbines. Energy 2012; 46(1); 62-71.

[7] Timmer WA and van Rooij RPJOM. Summary of the Delft University wind turbine dedicated airfoils. J Solar Energy Eng 2003; 125(4): 488-496. doi:10.1115/1.1626129

[8] Fuglsang P, Bak C. Development of the RIS $\varnothing$ wind turbine airfoils. Wind Energy 2004; 7:145-162. 
[9] Wang XD, Chen J, Shen WZ, Zhu WJ and Sørensen JN. Airfoils and methods for designing airfoils. Application No. PCT/EP2010/056810, International patent application.

[10] Tahani M, Kavari G, Masdari M, Mirhosseini M. Aerodynamic design of horizontal axis wind turbine with innovative local linearization of chord and twist distributions. Energy 2017; 131; 78-91.

[11] Cheng JT, Zhu WJ, Fischer A, García NR, Madsen J, Chen J, Shen WZ. Design and validation of the high performance and low noise CQU-DTU-LN1 airfoils. Wind Energy 2014; 17(12):1817-1833. DOI: $10.1002 /$ we. 1668.

[12] Wang XD, Shen WZ, Zhu WJ, Sørensen JN \& Chen, J. Shape optimization of wind turbine blades. Wind Energy 2009; 12 (8): 781-803. DOI: 10.1002/we.335.

[13] Vesel Jr. RW, McNamara J. J. Performance enhancement and load reduction of a $5 \mathrm{MW}$ wind turbine blade. Renewable Energy 2014; 66: 391-401. DOI:10.1016/j.renene.2013.12.019.

[14] Sartori L, Grasso F, Bottasso C, Croce A. Integration of airfoil design during the design of new blades. ICOWES 2013, Copenhagen, 17-19 June 2013.

[15] Swanson T, Isaac KM. Biologically inspired wing leading edge for enhanced wind turbine and aircraft performance. 6th AIAA Theoretical Fluid Mechanics Conference. AIAA 2011-3533.

[16] Oerlemans S, Fisher M, Maeder T and Kögler K. Reduction of wind turbine noise using optimized airfoils and trailing edge serrations. AIAA J 2009; 47(6):1470-1481.

[17] Manolesos M, Voutsinas SG. Experimental investigation of the flow past passive vortex generators on an airfoil experiencing three-dimensional separation. Journal of Wind Engineering and Industrial Aerodynamics 2015; 142: 130-148. DOI:10.1016/j.jweia.2015.03.020.

[18] Franco JA, Jauregui JC, Carbajal A, Toledano-Ayala M. Shape morphing mechanism for improving wind turbines performance. Journal of Energy Resources Technology, Transactions of the Asme 2017; 139 (5): 051214.

[19] Wind turbine dome and method of assembly. General Electric Company, Patent number 20150233342.

[20] Mohd-Yusof J. Combined immersed boundary/b-spline methods for simulation of flow in complex geometries. Center for Turbulence Research Annual Research Briefs 1997; 317-327. 
[21] Zhu WJ, Behrens T, Shen WZ, Sørensen JN. Hybrid immersed boundary method for airfoils with a trailing-edge flap. AIAA J 2013; 51 (1): 30-41. DOI: 10.2514/1.J051446.

[22] Mikkelsen R. Actuator disc methods applied to wind turbines. MEK-FM-PHD 2003-02. Technical University of Denmark.

[23] Michelsen JA. Basis3D - A platform for development of multiblock PDE solvers. Technical Report AFM 1992-05; Technical University of Denmark.

[24] Sørensen NN. General purpose flow solver applied over hills. RIS $\emptyset-R-827-(E N)$ 1995; Ris $\varnothing$ National Laboratory, Denmark.

[25] Behrens T, Shen WZ, Zhu WJ, Sørensen, JN, Sørensen, NN. Simulation of moving trailing edge flaps on a wind turbine blade using a Navier-Stokes based immersed boundary method. PhD thesis, DTU Wind, Denmark, 2011.

[26] Sørensen JN, Kock CW. A model for unsteady rotor aerodynamics. J Wind Engineering and Industrial Aerodynamics 1995; 58: 259-275.

[27] Hansen MOL, Aagaard MH. Review paper on wind turbine aerodynamics. J Fluids Engineering 2011; 133(11): 114001. DOI: http://dx.doi.org/10.1115/1.4005031

[28] Kalvig S, Manger E, Hjertager B. Comparing different CFD wind turbine modelling approaches with wind tunnel measurements. J Physics Conference Series 2014; 555.

[29] Sørensen JN, Shen WZ. Numerical modeling of wind turbine wakes. Journal of Fluids Eng 2002; 124(2): 393-399. doi:10.1115/1.1471361.

[30] Nilsson K, Shen WZ Sørensen JN, Breton SP, Ivanell S. Validation of the actuator line method using near wake measurements of the MEXICO rotor. Wind Energy 2015; 18(3): 499-514.DOI: http://dx.doi.org/10.1002/we.1714

[31] Shen WZ, Zhu WJ, Sørensen, JN. Validation of the actuator line/Navier Stokes technique using mexico easurements. The Scienceof Making Torque from Wind 2010; 227-234.

[32] Shen WZ, Zhang JH, Sørensen JN. The actuator surface model: A new Navier-Stokes based model for rotor computations. J Solar Energy Engineering 2009; 131(1): 011002. DOI: http://dx.doi.org/10.1115/1.3027502. 
[33] Menter, FR. Two-equation eddy-viscosity turbulence models for engineering applications. AIAA J 1994; 32(8): 1598-1605.

[34] Troldborg N, Bak C, Aagaard Madsen H, Skrzypinski WR. Danaero MW: Final report. DTU Wind Energy No. 0027(EN). ISBN 978-87-92896-39-1. 2013.

[35] Peeringa J, Brood R, Ceyhan O, Engels W, Winkel G. Upwind 20MW wind turbine pre-design. ECNE-11-017. 2011.

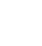


Table 1 The integrated viscous force, pressure force and aerodynamic torque.

\begin{tabular}{|c|c|c|c|}
\hline & Viscous force [N] & Pressure force [N] & Torque $[N m]$ \\
\hline Original rotor & $3.9411 \mathrm{E}+02$ & $2.4562 \mathrm{E}+05$ & $8.4080 \mathrm{E}+05$ \\
\hline Rotor with disc & $3.2608 \mathrm{E}+02$ & $2.5508 \mathrm{E}+05$ & $8.5469 \mathrm{E}+05$ \\
\hline
\end{tabular}

406

407

408

409

410

411

412

413

414

415

416

417

418

419

420

421

422

423

424

425

426 
428

429

430

431

432

433

434

435

436

437

438

439

440

441

442

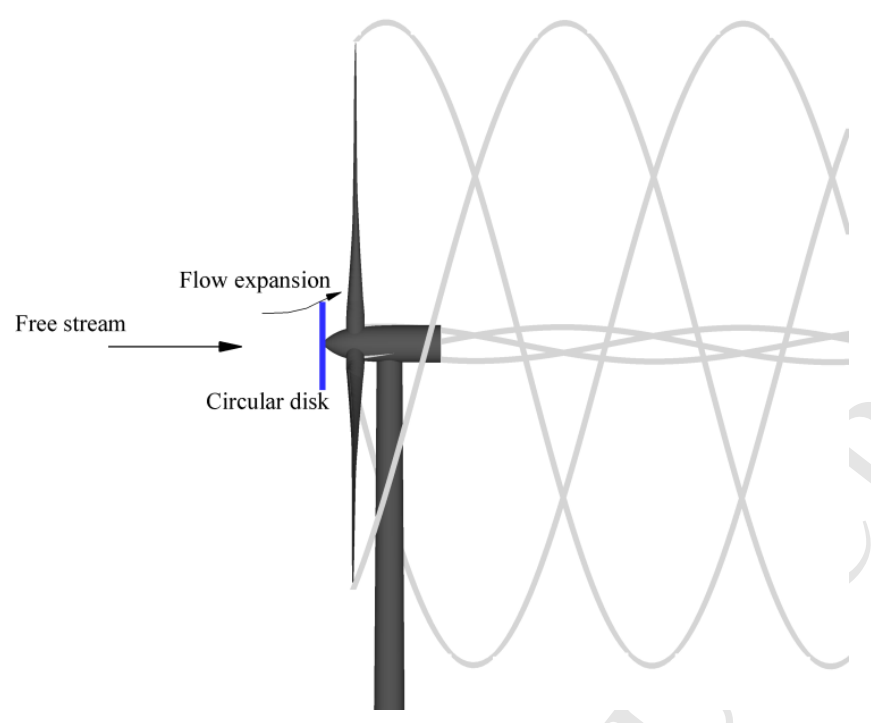

Fig. 1 Sketch of a wind turbine with an added disc in front. 
443

444

445 447

448

449

450

451

452

453

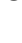

51
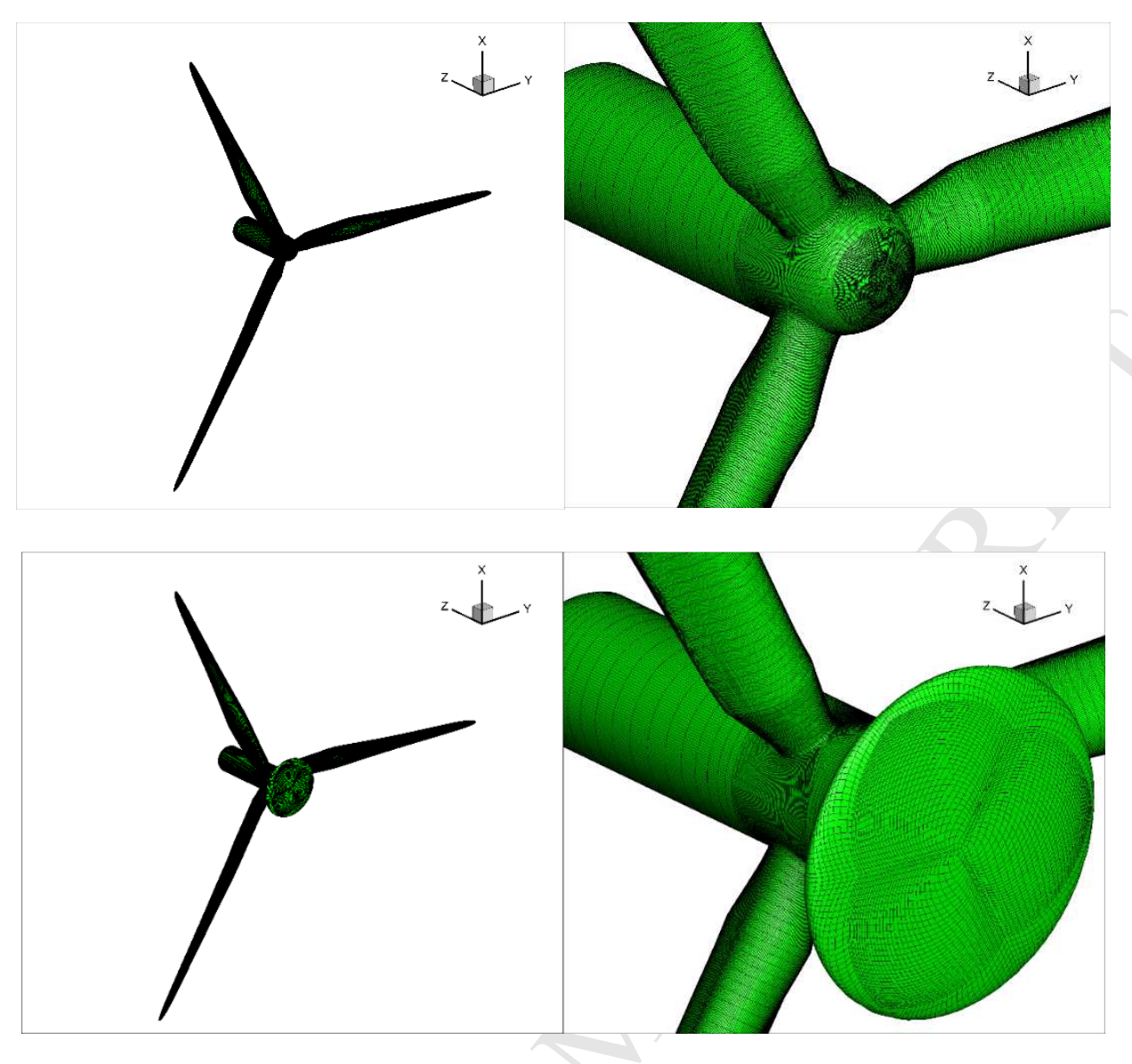

Fig. 2 Surface mesh shown in every two grids: the original rotor and the rotor with a disc. 


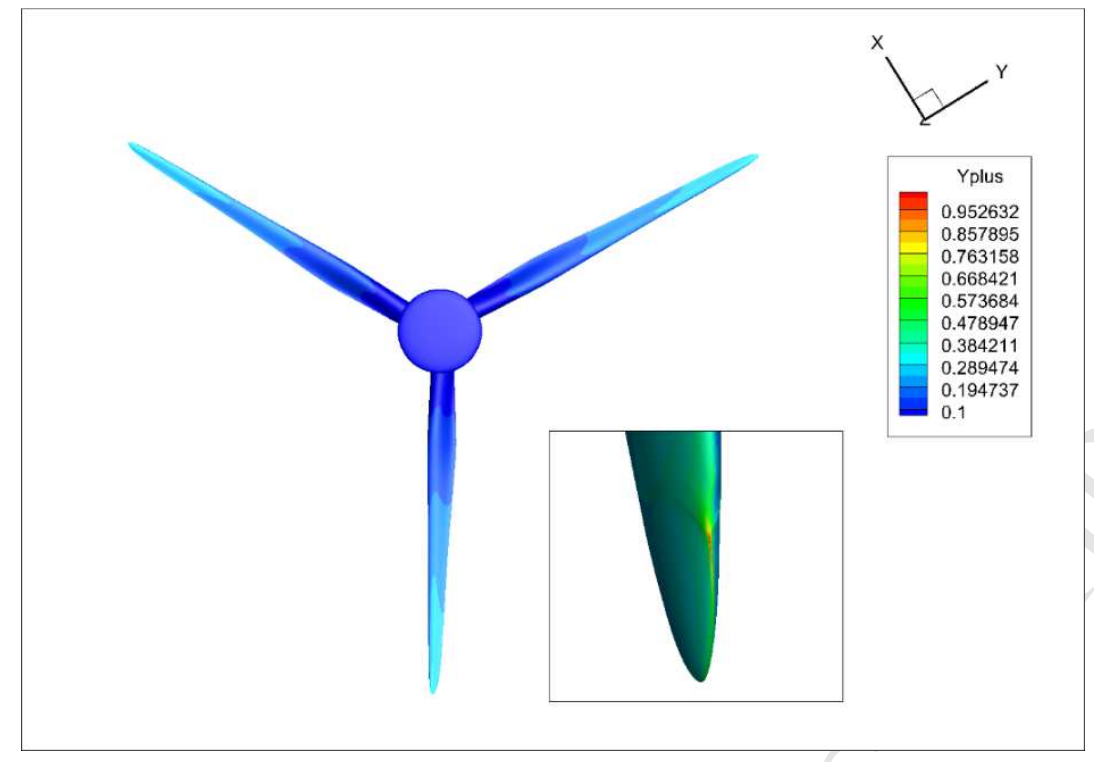

455

Fig. 3 Dimensionless wall distance on blade surface.

456

457

458

459

460

461

462

463

464

465 

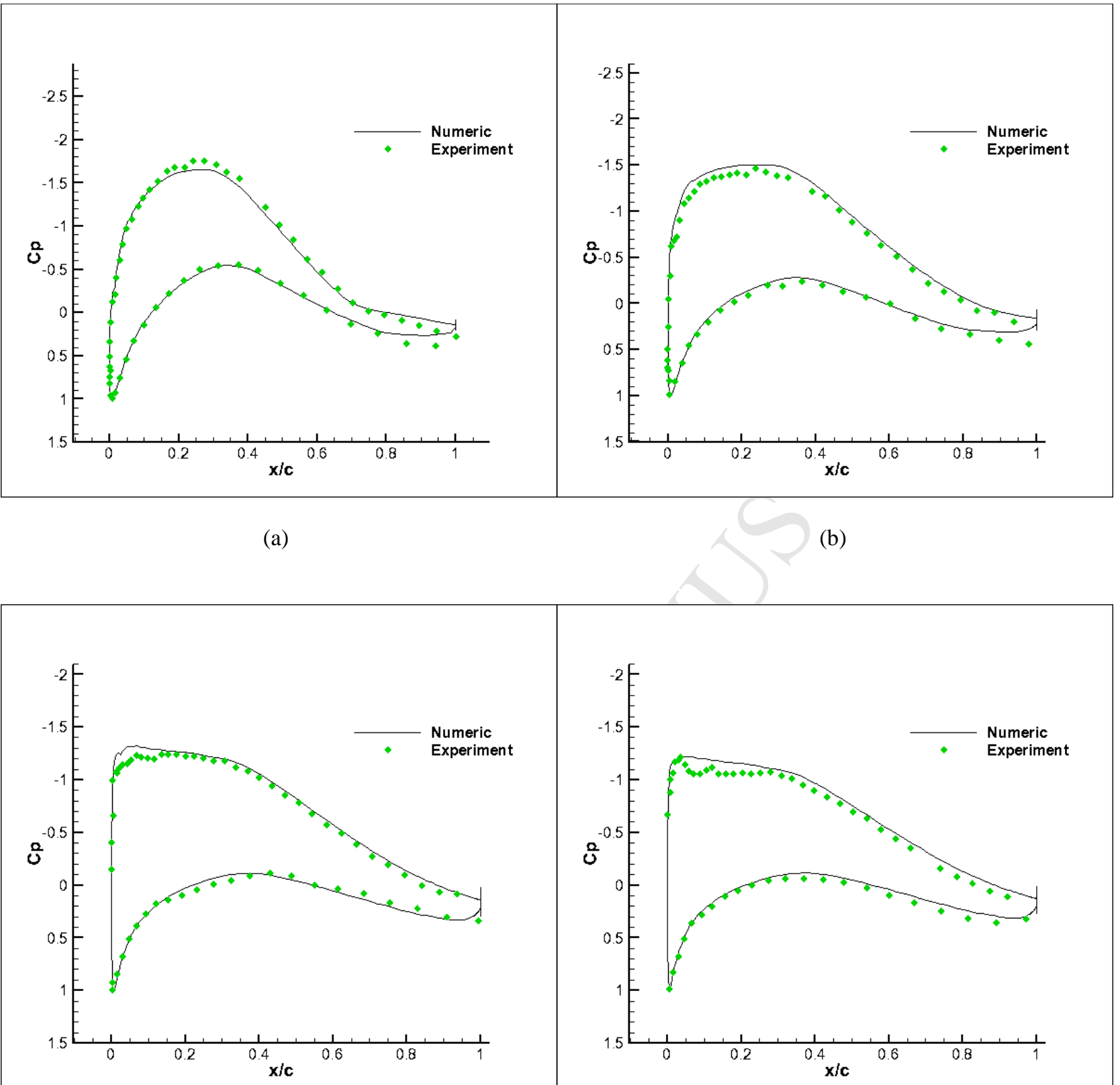

Fig. 4. Comparisons of the surface pressure coefficient distribution at four measured locations: (a) $r=13 \mathrm{~m}$; (b) $r=19 m$; (c) r=30m and (d) r=37m. 


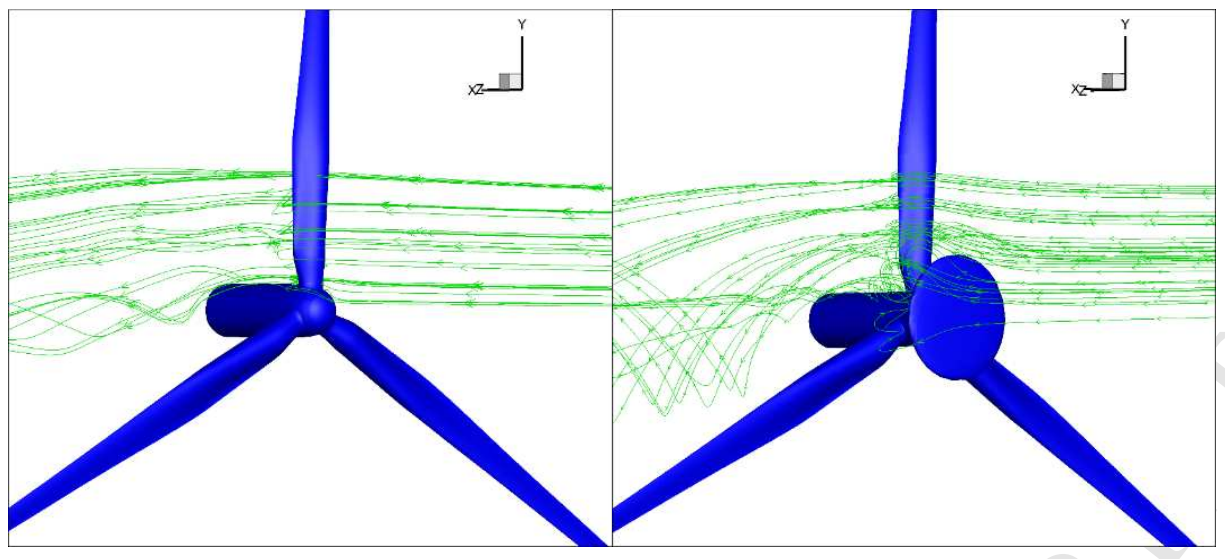

475

Fig. 5 3D streamlines passing through one of the blades.

476

477

478

479

480

481

482

483

484

485

486 
487

488

489

490

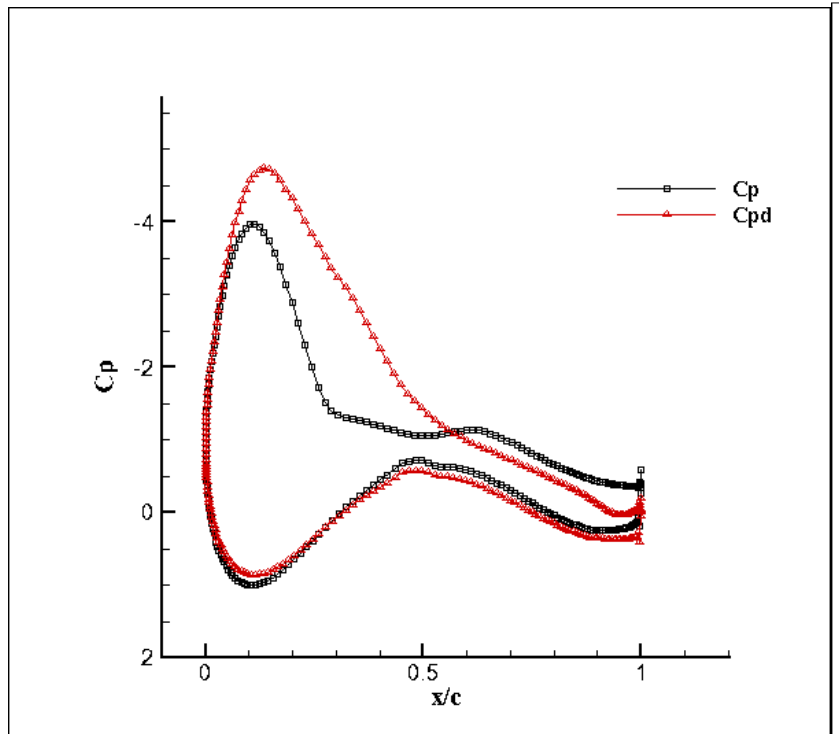

(a)

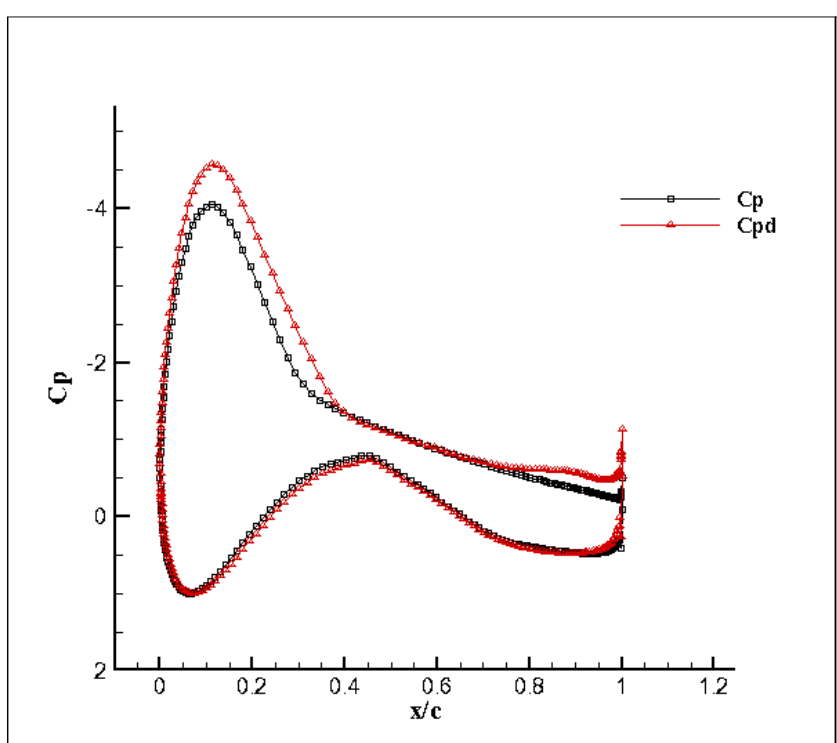

(c)

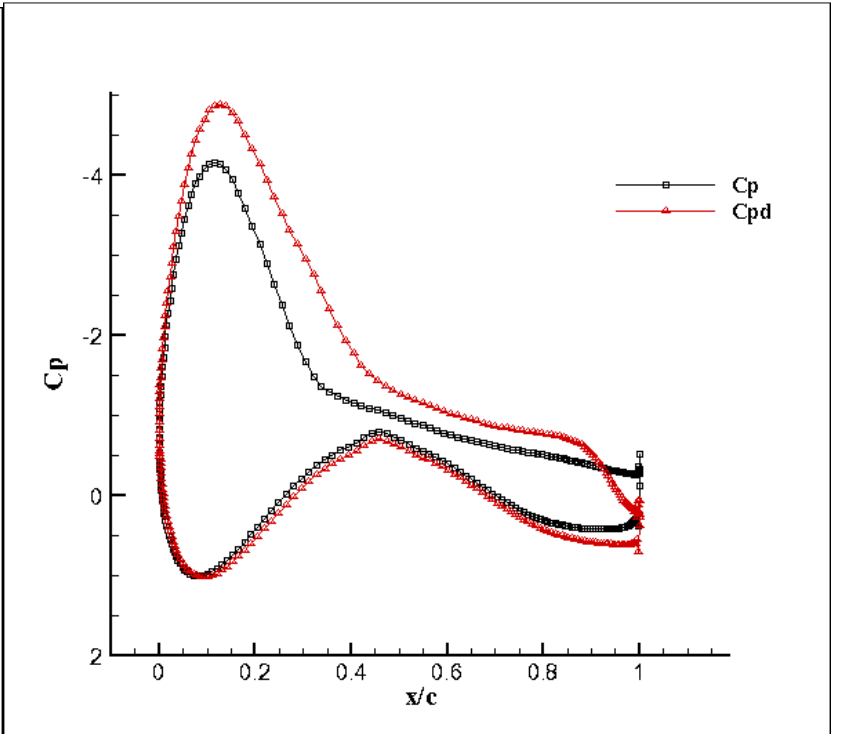

(b)

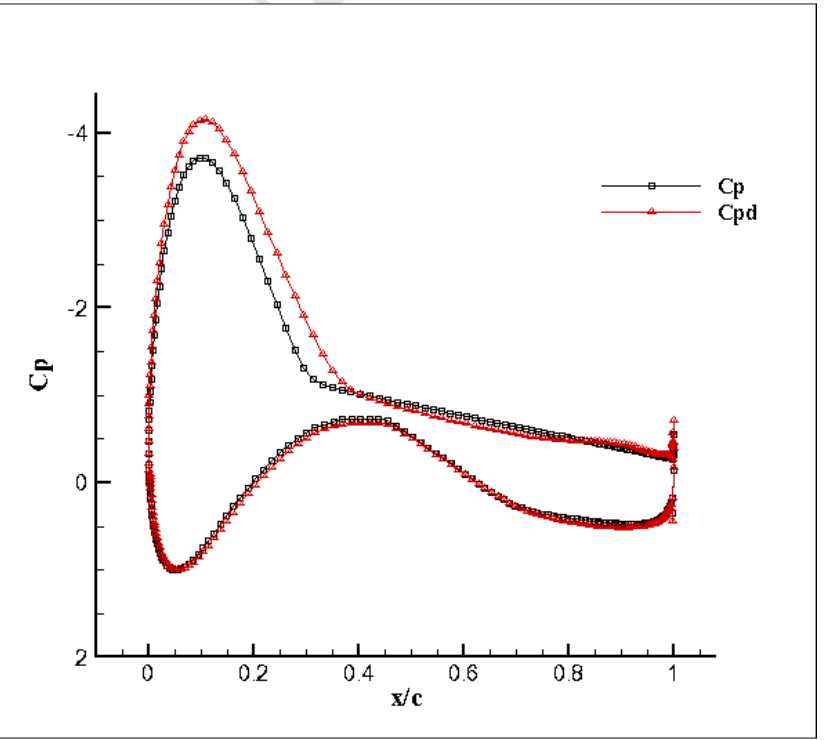

(d)

Fig. 6 Comparisons of distributions of surface pressure coefficient, from root towards tip: (a) r=6m; (b) r=7m; (c) r=8m; (d) r=9m; (e) r=10m; (f) r=12m; (g) r=14m; (h) r=16m; (i) r=18m; (j) r=30m. 


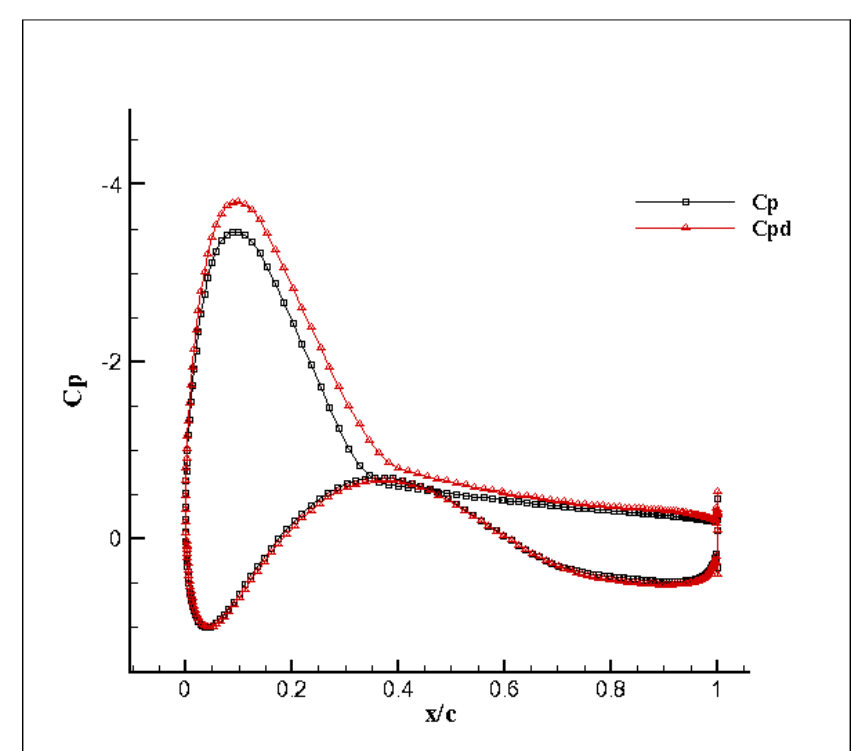

(e)

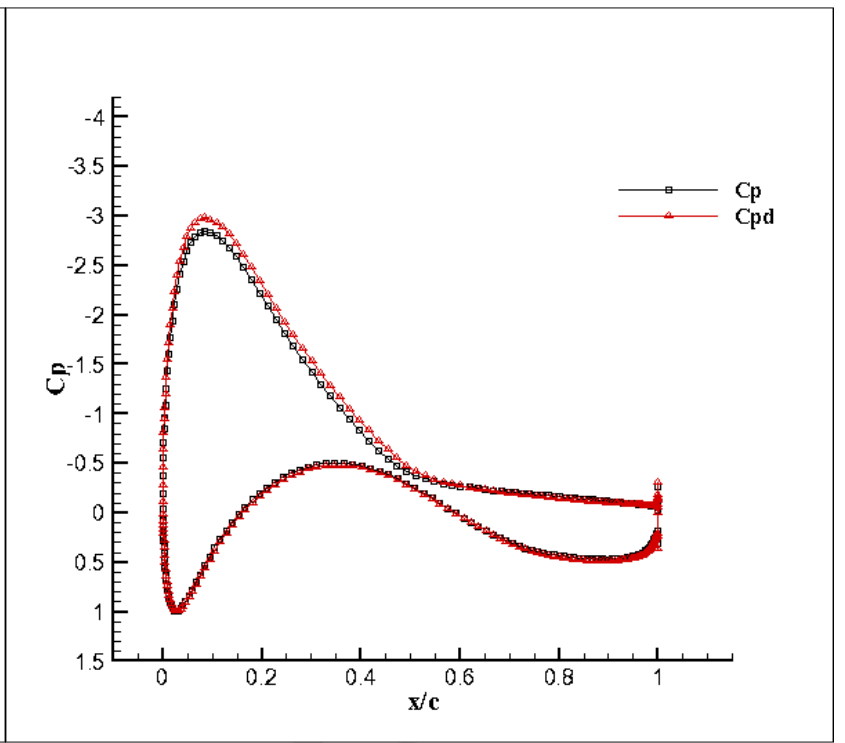

(f)

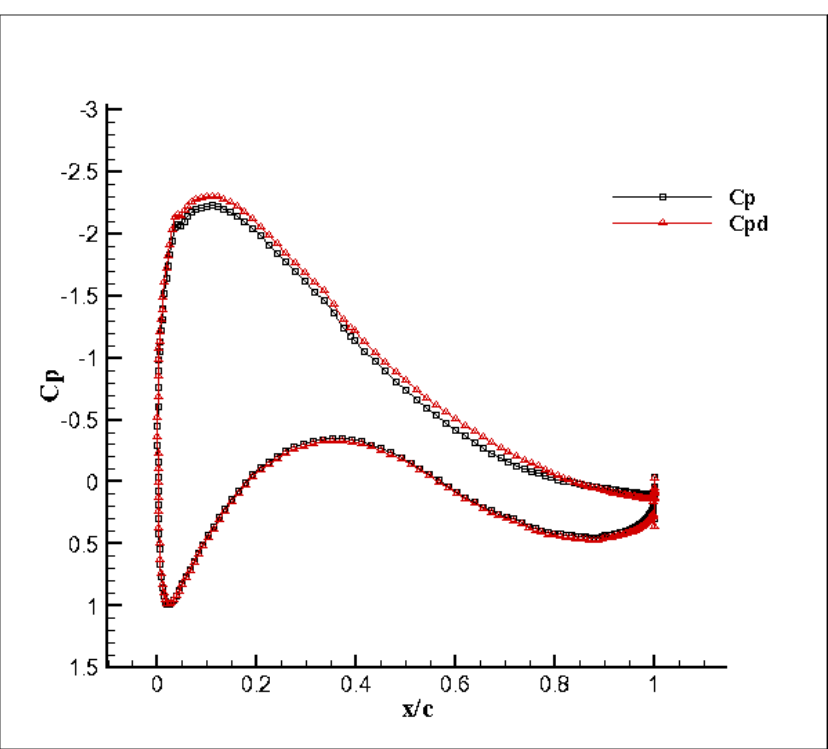

(g)

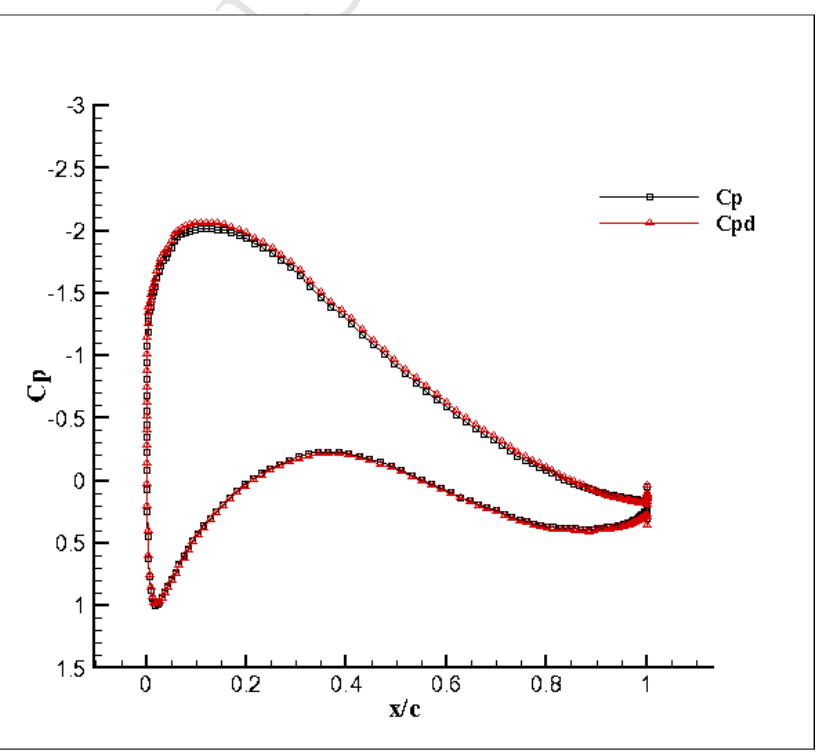

(h)

Fig. 6 Comparisons of distributions of surface pressure coefficient, from root towards tip: (a) r=6m; (b) r=7m; (c) $r=8 m$; (d) $r=9 m$; (e) $r=10 m$; (f) $r=12 m$; (g) r=14m; (h) r=16m; (i) r=18m; (j) r=30m. 


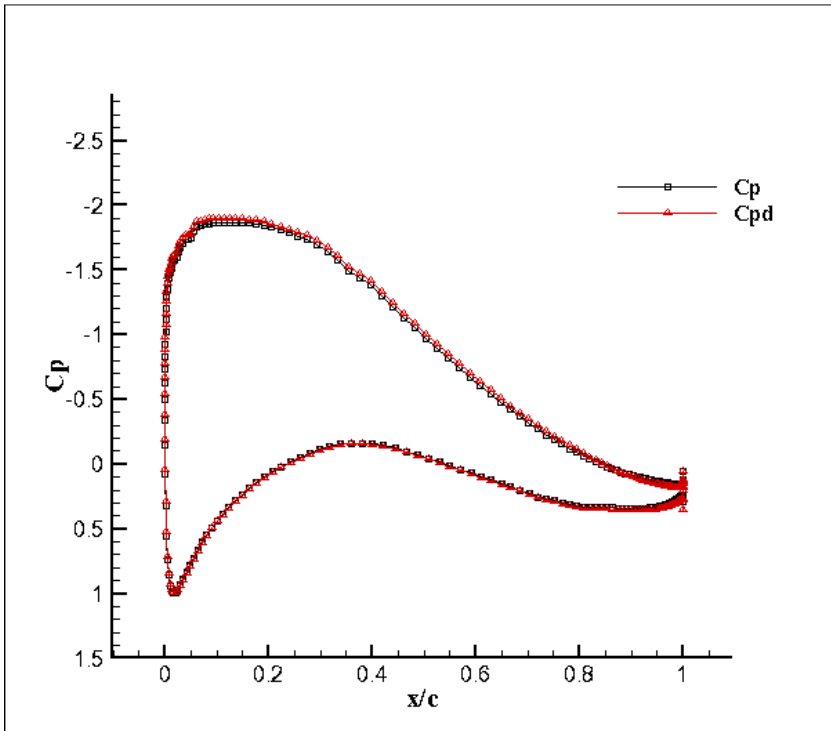

(i)

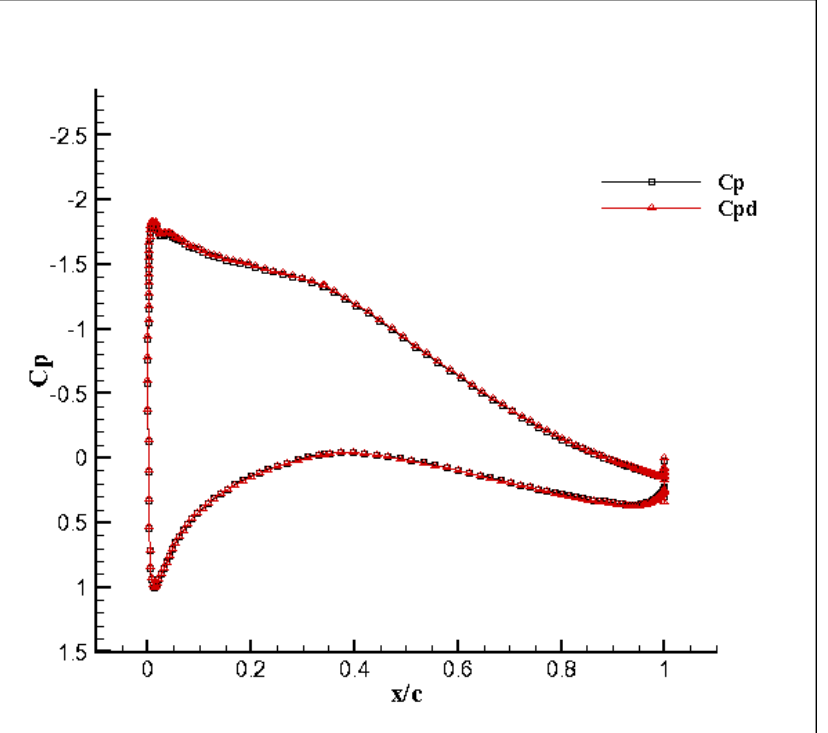

(j)

Fig. 6 Comparisons of distributions of surface pressure coefficient, from root towards tip: (a) r=6m; (b) r=7m; (c) $r=8 m$; (d) r=9m; (e) r=10m; (f) r=12m; (g) r=14m; (h) r=16m; (i) r=18m; (j) r=30m. 


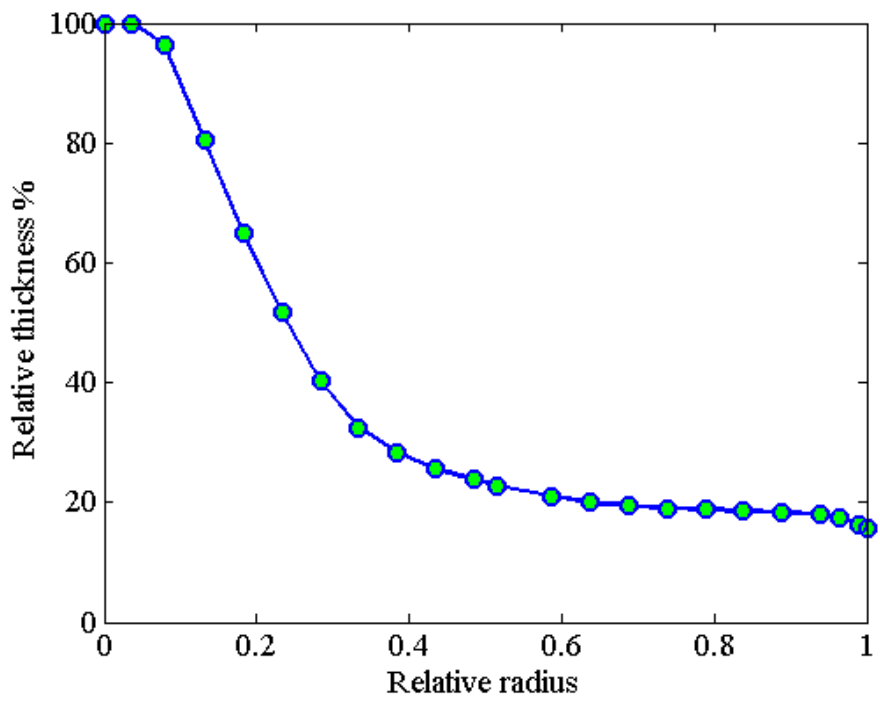

Fig. 7 Normalized blade thickness distribution. 


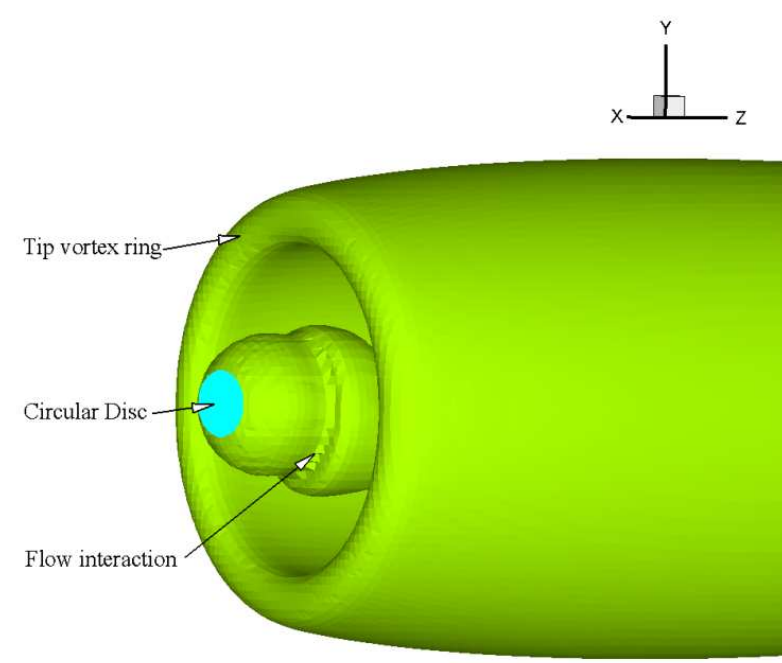

Fig. 8 Combined iso-vorticity of the small circular disc and the rotor disc.

531

532

533

534

535

536

537

538

539 

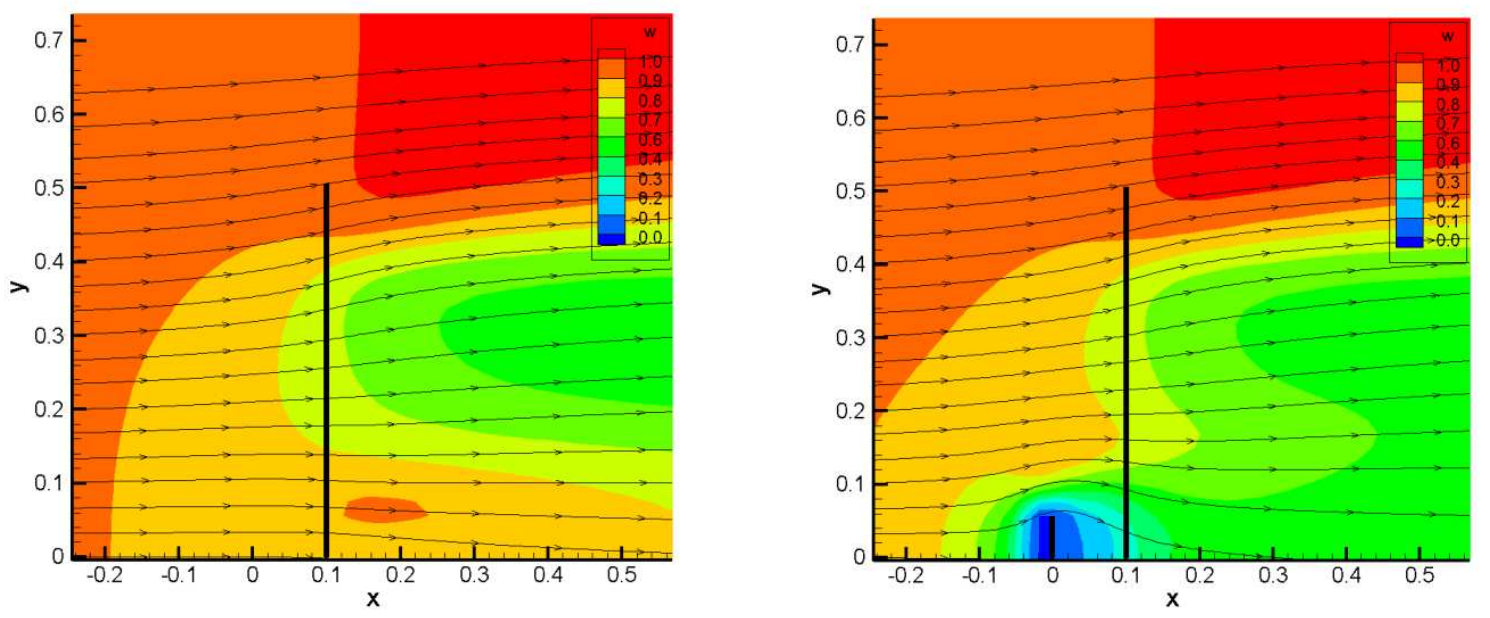

Fig. 9 Comparisons of the axial flow over the original and the optimized rotor system. 


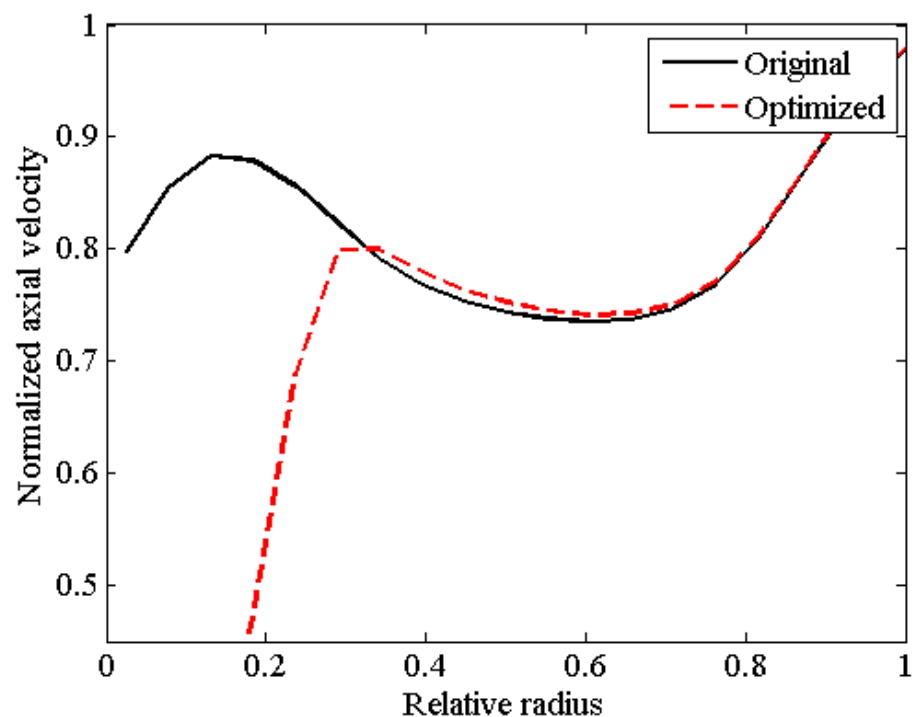

Fig. 10 Comparison of axial velocity distributions along the blades. 


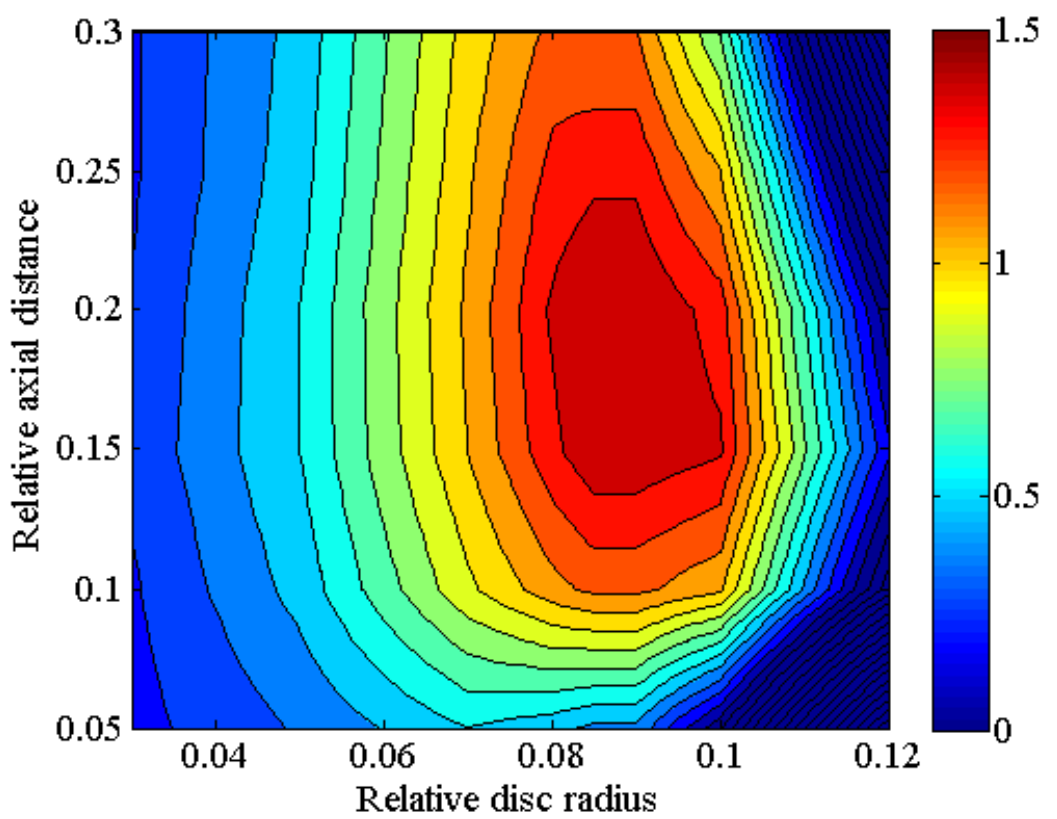

Fig. 11 Test matrix of the aerodynamic power coefficient in percentage.

564

565

566

567

568

569

570

571

572

573

574 


\section{Highlights}

- Maximizing energy capture is achieved from an existing horizontal axis wind turbine with smart design.

- The novel blade root design is more cost effective and easy to implement.

- Hybrid numerical methods are implemented to improve computational efficiency. 